\title{
CORRIGENDUM
}

\section{Cytosolic PKM2 stabilizes mutant EGFR protein expression through regulating HSP90-EGFR association}

Y-C Yang, T-Y Cheng, S-M Huang, C-Y Su, P-W Yang, J-M Lee, C-K Chen, M Hsiao, K-T Hua and M-L Kuo

Oncogene (2017) 36, 4234; doi:10.1038/onc.2017.18; published online 20 March 2017

Correction to: Oncogene (2016) 35, 3387-3398; doi:10.1038/onc. 2015.397; published online 26 October 2015

Since the publication of this article the authors noticed an inadvertent mistake in the representative pictures of colony formation assay in Figure 2c. Due to unintentional errors made during the preparation of figures, images used in Figure $1 \mathrm{~b}$ have been duplicated in Figure 2c. The authors wish to replace Figure $2 \mathrm{c}$ with the below correct version.

The authors also noticed the error in one of the subheadings under the Supplementary Methods section 'Treated cells were seeded on 6-well plates at a density of 1000 cells per well, and allowed to grow for 10 to 14 days' has now been corrected to 'Treated cells were seeded on 6-well plates at a density of 1500 cells per well, and allowed to grow for 10 to 14 days'.

The authors apologize for any inconvenience caused by these errors and confirm that the conclusions drawn from this research are not affected.

The below figure shows the raw data of representative pictures. (The number 161 indicates the $3^{\prime}$-UTR sh-PKM2 clone.)
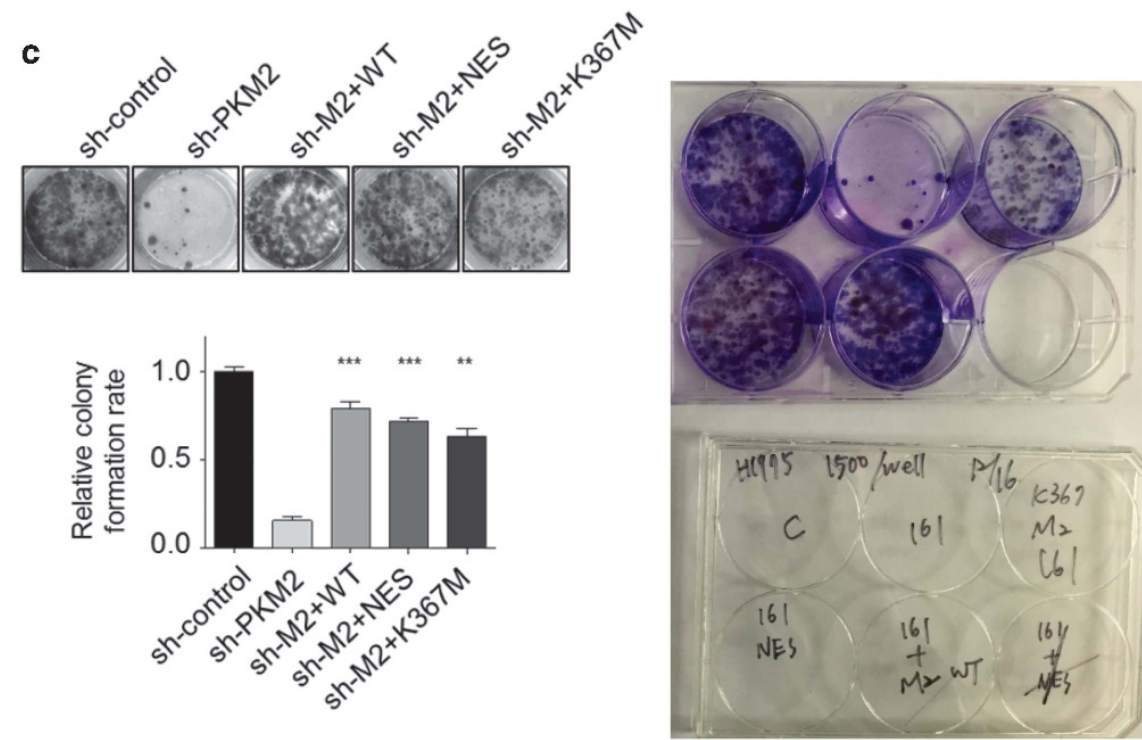

Figure 2. 